\title{
A National Language Policy for Zimbabwe in the Twenty-first Century: Myth or Reality?
}

\author{
Raphael Nhongo \\ Department of African Languages and Culture, Midlands State University, Zimbabwe
}

\begin{abstract}
The thrust of the paper is on the activities that have taken place in Zimbabwe concerning the formulation of a plausible national language policy. The paper looks at how the current Zimbabwe's language situation affects its social, economic, political and educational development. The paper begins by tracing the history of language activities in Zimbabwe from the pre-colonial era and linking such activities with those that are taking place currently and how such activities have had an influence in development. The paper problematizes the idea of language policy and planning activities taking place in Zimbabwe through focusing on the suggestions, declarations, recommendations and acts that have so far been put in place concerning the language issues. The paper concludes by scrutinizing the link between multilingualism, politics of the day and meaningful development.
\end{abstract}

Index Terms - language policy, language planning, English language, global language, twenty-first century

\section{INTRODUCTION}

This paper looks at the language planning activities that are taking place in Zimbabwe and the possibility of having a clear national language policy in the twenty-first century. This article begins by looking at the language situation and the language planning activities that have taken place in Zimbabwe dating back to the pre-colonial era. The paper scrutinizes the suggestions, acts, recommendations and declarations that have been put in place regarding language issues in Zimbabwe. The act here referred to is the 1987 education act of Zimbabwe and the declarations are those that have come into being as resolutions to meetings and conferences especially involving the African heads of states and government, ministers, and academics. The recommendations are those that have been put in place by large governing bodies such as the United Nations (UN). The main focus of the paper is language and development, but the paper goes a step further to problematize the issue of language and politics and language and nationalism. The paper concludes by looking at the possibilities of having a clear and an all encompassing national language policy in Zimbabwe in the twenty-first century at a time when English is fast becoming a global language.

\section{Language Situation in Zimbabwe from the Pre-colonial Era to Date}

At the moment Zimbabwe has more than eleven indigenous languages and these include Shona, Ndebele, Tonga, Nambya, Kalanga, Sotho, Hwesa, Sena, Chikunda, Doma, Tswana, Tswawo/Khoisan, Barwe, Fingo/Xhosa, and Chewa (Hachipola, 1998) and all of them are marginalized except for Shona and Ndebele. The two 'major' indigenous languages of Zimbabwe which are Shona and Ndebele can be identified in a true sense as hybrid languages. Shona being a hybrid of what are now referred to as dialects which include Zezuru, Ndau, Korekore, Manyika and Karanga after the unification by Clement Doke in 1931. Ndebele was originally Nguni or better still Zulu but got the influence of Kalanga, Sotho and Shona as Mzilikazi, the leader of the Ndebele incorporated some people from these other groups into his group.

The power of language can be seen from how Mzilikazi built the Ndebele state by incorporating people from other linguistic groups during the pre-colonial era. As Mzilikazi moved from Zululand in the first quarter of the nineteenth century (Hadebe, 2002), he expanded his group by incorporating members from the other groups through force, consent and coercion. The groups whom some of their members were incorporated into Mzilikazi's group include the Sotho; the Ndebele of South Africa; that is Amanzunza and Amanala; Tswana; Kalanga; the Shona, particularly the Karanga and some other groups not mentioned here. However, those incorporated into Mzilikazi's group had to forego their own languages and adopt the Nguni language which is now called Ndebele. Discarding the native language and adopting Zulu for those incorporated was Mzilikazi's powerful strategy for building nationhood. The quest for identifying as one was achieved through the adoption and use of one language which is today called Ndebele. Once people identify themselves as one then they form a nation. It has to be noted that this process was not a friendly one because the one incorporated had to comply with the requirements of Mzilikazi's rule failure to which meant resistance. Some people from other groups surrendered themselves to Mzilikazi's group so as to seek protection from the raids.

This then shows that nationhood that is built through language is not a noble one because one state one language means forcing some members of the state to comply even against their own will. One is not born with a language so that he can later on forego it for certain other advantages, such an encounter is tantamount to total disposition. Even though 
Mzilikazi built the Ndebele state through having those incorporated adopting the Ndebele language, it did not mean that they became equal with the Ndebele who came from Zululand. Those incorporated along the way were labeled as Abenhla and those incorporated in the present day Zimbabwe were labeled as Amahole. These two identity markers Amahole and Abenhla carried derogatory connotations, those of not being original. This kind of caste meant that in the Ndebele state there were what Mamdani (1996) calls the citizens and the subjects.

Then came colonialism in 1890, when what is today known as Zimbabwe went under the British rule and came to be called Southern Rhodesia. The following encounter will show how powerful language is since Shona and Ndebele languages were used in achieving total colonization of the country and its peoples. The demarcation of Rhodesia into provinces with the terms Matabeleland, Mashonaland and Midlands meant that in areas where the province was Matabeleland, the expectation was that it should be Ndebele that is dominant and is used there; Mashonaland meant that it is the Shona language that was expected to be used there and in the Midlands, it was both Shona and Ndebele languages that were expected to be used there. Of interest to note is that in some parts of Matabeleland, there was totally no Ndebele speaker at the time of colonization. The Ndebele people were concentrated around what today is Bulawayo, the second largest city of Zimbabwe. In Matabeleland North, there were Tonga people in Binga, Nambya in Hwange and Kalanga in Tsholotsho. In Matabeleland South, there were Kalanga in Plumtree and Kezi, Sotho in Gwanda and some parts of Beitbridge and Venda in Beitbridge. All these languages mentioned here are mutually unintelligible with Ndebele. In Mashonaland West again in Chiredzi there was the Shangani people whose language is also mutually unintelligible with Shona.

It is clear, then that Shona and Ndebele were used to strengthen colonialism. Even the missionaries promoted only Shona and Ndebele and thus the bible was translated into these two languages in Zimbabwe. In industries, the dominant indigenous languages were also Shona and Ndebele. It is clear then that the dominance of Ndebele and Shona today dates back to the inception of colonization of Zimbabwe.

\section{ACts, Declarations, Suggestions And Recommendations}

A number of suggestions and declarations have been put forward regarding the use of languages not only in Zimbabwe but in Africa and beyond. Zimbabwe has its own education act which is one of the clear signs that language matters are a cause for concern.

In 1987, there came an Education Act which stipulates that:

1. The three main languages of Zimbabwe, namely Shona, Ndebele and English, shall be taught in all primary schools from the first grade as Follows:

a. Shona and English in all areas where the mother-tongue of the majority of the residents is Shona or

b. Ndebele and English in all areas where the mother tongue of the majority of the residents is Ndebele.

2. Prior to the fourth grade, either of the languages referred to in paragraph (a) or (b) of sub-section (1) may be used as the medium of instruction, depending upon which language is more commonly spoken and better understood by the pupils.

3. From the fourth grade, English shall be the medium of instruction provided that Shona or Ndebele shall be taught as subjects on an equal-time allocation as the English language.

4. In areas where minority languages exist, the Minister may authorise the teaching of such languages in primary schools in addition to those specified in sub-section (1), (2) and (3). (Part XII, 62, p.255)

This Education act was revised in 1990, but still there were no notable changes. Although it was revised it remains with a lot of questionable loopholes. Although this policy was put in place, many schools in the country in areas where minority languages exist did not implement it due to various reasons which are going to be outlined later.

Mutasa (2006) points out that there are three declarations that have been made concerning the issue of languages in Africa. First there was The Language Plan of Action for Africa followed by The Harare and then The Asmara Declaration.

The heads of state and government met of the Organization of African Unity (OAU), now African Union (AU) met in Ethiopia in Addis Ababa from the $28^{\text {th }}$ to the $30^{\text {th }}$ of July in 1986 it was agreed that "language is at the heart of a people's culture" (OAU, 1986) and that economic and social development can be accelerated through the use of indigenous African languages. The discussions evolved around the following key notions:

- That Africa needs to assert her independence and identity in the field of language;

- That African states need to take practical action to accord their indigenous languages their rightful official role as provided for by the Cultural Charter for Africa which was arrived at in Lagos;

- That each sovereign state has the right to devise a language policy that reflects the cultural and socio-economic realities of its country;

- That the adoption and promotion of African languages as official languages of the state can be achieved when there is political will;

- That the promotion and adoption of African languages as official languages of the state is of advantage in education, in politics, cultural and political affairs of the state;

- That mass literacy campaigns cannot be achieved without the use of African languages;

- That the promotion of cross boarder languages is a vital factor in achieving African unity; 
- That in coming up with a national language policy, multilingualism must be emphasized; (OAU, 1986).

The following were the aims and objectives of the Plan of Action:

- To encourage each and every Member State to have a clearly defined language policy;

- To ensure that all languages within the boundaries of Member States are recognized and accepted as a source of mutual enrichment;

- To liberate the African peoples form undue reliance on the utilization of non-indigenous African languages as the dominant, official languages of the state in favor of the gradual take-over of appropriate and carefully selected indigenous African languages in this domain;

- To ensure that African Languages, by appropriate legal provision and practical promotion, assume their rightful role as the means of official communication in the public affairs of each Member State, in replacement of European Languages, which have hitherto played this role;

- To encourage the increased use [of] African languages as vehicles of instruction at all educational levels;

- To ensure that all the sectors of the political and socio-economic systems of each Member State is mobilized in such a manner that they play their due part in ensuring that the African language(s) prescribed as official language(s) assume their intended role in the shortest time possible;

- To foster and promote national, regional and continental linguistic unity in Africa, in the context of multilingualism prevailing in most African countries.

The Harare declaration came as a result of the Intergovernmental conference on language policies in Africa held in Harare, Zimbabwe from the $17^{\text {th }}$ to the $21^{\text {st }}$ of March 1997 organized by the United Nations Education, Cultural and Scientific organization. At the conference it was declared that the following anomalies would be corrected:

- The richness of linguistic diversity in Africa and its potential as a resource for all types of development is not being recognized;

- The urgent need for African States to adopt clear policies for the use and development of mother tongues;

- Use of African languages is a prerequisite for maximizing African creativity and resourcefulness in development activities;

- The language policies introduced since independence have generally favored the colonial languages by setting up language structures that confer a monopoly of official status to the languages of the former colonial powers;

- Most of the recommendations made to correct this situation have not been implemented;

- Only very few African countries have clear and comprehensive language policies and even fewer have enshrined the stipulations of such policies in their constitutions;

- Language policy decisions are actually political decisions that can only be taken up by national governments (UNESCO, 1997).

The following are the recommendations that came out during the conference:

- Each country should have a clear Language Policy Document within which every language spoken in the country should find its space;

- Guidelines for Language Policy formulation should be sanctioned by legislative action;

- Every country's policy framework should be flexible enough to allow each community to use its language side-byside with other languages while at the same time giving provision to wider communication;

- A language policy formulating and monitoring body/institution should be established within each country (UNESCO, 1997).

The Asmara declaration came at the conclusion of a conference held in Asmara, Eritrea from the $11^{\text {th }}$ to $17^{\text {th }}$ of January 2000 where the discussion centered on examining "the state of African languages in relation to government policy and administration, publishing and public education, scholarship and intellectual (re)presentation and to the question of development more generally" (Mazrui, 2012). The title of the conference was Against All Odds and the discussion was on African languages being threatened by the European languages especially English. At the end of the conference a declaration was made on African languages and literatures and the following were contents of the declaration that were put forth by the writers and scholars:

- African languages must take on the duty, the responsibility and the challenge of speaking for the continent;

- The vitality and equality of African languages must be recognized as a basis for the future empowerment of African peoples;

- The diversity of African languages reflects the rich cultural heritage of Africa and must be used as an instrument of African unity;

- All African children have the unalienable right to attend school and to learn in their mother tongues. Every effort should be made to develop African languages at all levels of education (The Asmara declaration on African Languages and Literatures, 2000).

There are many other declarations which were made at this conference, but those included here are those that are much relevant to this article.

The declarations from the Language Plan of Action for Africa by the OAU now African Union (AU); by UNESCO in the Harare Declaration; and by writers and scholars in the Asmara Declaration are very interesting in that years after 
these declarations have been made Zimbabwe still seems to be lagging behind in terms of implementation. This then raises the question of whether attaining a clear language policy in Zimbabwe would be a myth or reality.

These declarations are also open to criticism. First is clear in all these declarations that in all of them there are blames of the dominance of ex-colonial languages. One wonders whether is the colonialists who are still ruling Africa or it's the Africans themselves. Who should implement policies in Africa? Is it the former colonizer or it is the current rulers? When African countries gained independence the former colonizers did not come back and say continue using our languages, but decades after independence Africans are still concentrating on blaming the dominance of the European languages. If Africans feel that there can be development through the use of African languages, then who is stopping the use of those African languages. Concentrating on blaming would not bring development to Africa instead the African countries should know what they really want and then find ways of achieving their goals and they should also design clear policies of relating with their partners in a bid to achieve development.

The declarations are also questionable again as they also emphasize on the dominance of the ex-colonial languages. They all declare that each African state should promote the use and development of every language that falls within its borders, but they overlook the reality that some indigenous African languages suppress and dominate other indigenous languages of Africa. The case in point is that of Shona and Ndebele in Zimbabwe which dominate other languages which are now being labeled as minority. Shona and Ndebele dominate such languages as Kalanga, Venda, Tonga, Nambya, Shangani, Sotho, Chikunda, Chewa and some others not mentioned here. If such circumstances are ignored then, African governments would always be reluctant in formulating clear language policies because there is nothing that would be pushing them since the first languages of those in power are always the ones that dominate and are recognized in the unofficial policies. Phillipson (1992) observes that "Whether the decisions taken serve the interests of the mass of the population as well as the elites will depend on the nature of the state in question, and the degree of popular participation in decision making" (p. 84). The good thing about these declarations is that they contain sentiments of the realization that governments are the ones that are responsible for policy formulation. Development will therefore only be peculiar to those whose languages dominate; those whose first languages are perceived to be inferior would not fully participate in development because of their perceived inferiority complex. They will always be left out in the periphery and would not be part of development processes such as education, economics, politics and so on.

The Harare declaration leaves one with a lot of questions than answers if Zimbabwe would be able to attain a clear national language policy in the twenty-first century. The conference took place in Harare, Zimbabwe in 1997 and today, more than a decade after the declaration nothing contained in the declaration has taken place. Zimbabwe should have taken the initiative in implementing what was declared since the declaration carries the name of its capital city. Mutasa (2006) points out that what hinders development in Africa is planning without action. If such conferences are held and a lot of suggestions come out which at the end are not implemented then that is a clear sign of stalemate in development. With such a scenario having taken place in Zimbabwe, then one is left wondering if attaining a national language policy in Zimbabwe would be a myth or a reality.

\section{Language and Educational Development in Modern Zimbabwe}

This section looks at the perceptions of scholars and people in general regarding language issues in education in the modern day Zimbabwean society. The education act of 1987, which is outlined in 1.3 above, is the only official written document regarding language use in Zimbabwe. In many African countries there are no national official language policy documents but what exists are just education acts and policies. This has been inherited from the colonial governments.

During the colonial era in Zimbabwe, the indigenous languages were not recognized in education. From a research carried out by Mumpande (2006), it is apparent that the other indigenous languages, now called the marginalized languages, were taught at lower levels of primary schooling until the early 1960s when the Southern Rhodesian leader unilaterally declared independence from Britain. From then on the only indigenous languages that were taught in schools were only Shona and Ndebele. When Zimbabwe gained independence in 1980, the country continued with the Rhodesian policies. The indigenous linguistic groups other than Shona and Ndebele were labeled as minority and they started contesting against that labeling in the late 1980s (Mumpande, 2006). Although Shona and Ndebele were the only recognized indigenous languages, English remained the dominant official language. More prestige was attached to the English language and those who could speak English were accorded higher social and economic status. Rassool et al (2006), and Guo and Beckett (2007) point out that fluency in English has become associated with being educated and therefore seen as a leeway to upward social mobility. The dominance of English in education has continued into the twenty-first century and African countries are now seeing no need to develop their own indigenous languages or to spend time and resources in trying to come up with national language policies since English is regarded as a window of opportunities.

Rassool et al (2006), note that in South Africa in the context of the Bantu Education, African languages were stigmatized as "other", and thus inferior in educational policy framework. They go on to point out that The Bantu language syllabus, Joint Matriculation Board (1979) stated that: 
Because the Bantu languages differ so much from the European languages it is necessary that the Bantu child should not view his (sic) mother tongue as if it were a European language. He must therefore be taught that his mother tongue has its peculiar character, which cannot be derived from European languages. He has to learn that his mother tongue is much more bound up with form, that in its system of writing it does not necessarily follow the European languages... (Rassool et al 2006).

The legacy of English in most African countries such as South Africa, Zimbabwe, Zambia, Malawi, Kenya, Botswana, etc was inherited from the colonial period and this partnered with it becoming a global language results in the underdevelopment of African indigenous languages. Sure and Webb in Webb and Sure (2000), observe that although the use of colonial languages in education has led to serious problems, it has also brought with it "enormous advantages such as access to knowledge, creativity and entertainment of the entire western world as well as global trade and commerce". The African languages are now viewed as inferior and there is no motivation amongst policy makers in developing these indigenous languages and even including them in the learning of other subjects such as agriculture, science, mathematics, geography and so on. Engin (2006) is of the view that "The motivation of the learners how ready and eager they are to get more information and to increase their ability to understand, write, and speak the second language" (p.1036). Learners can be motivated when learning in English because they know that there are gains at the end.

In some situations, despite the efforts by government authorities and authorities in institutions of learning to have children learning in indigenous languages, parents and even the children resist. In Botswana, private schools attract parents to send children to their schools by using the phrase "English Medium" when advertising their schools. Peresuh and Masuku (2002) have observed that in Zimbabwe, parents prefer their children to enroll in English medium schools because of the perceived high status of English even at elementary levels. In 2010, Zimbabwe started considering a compulsory four subject pass rate in all primary schools which are English, Shona/Ndebele, Mathematics and English. Those who do not pass Ndebele/Shona are now considered as having failed and this has seen the elitist schools' pass rate dropping way below those considered to be of people of low class in 2011. Peresuh and Masuku (2002) note that the lack of pride in the Zimbabwean children's primary languages has resulted in poor performance in Shona and Ndebele. However at ordinary level (O' level), for one to be considered as having passed, the candidate must have scored a grade $\mathrm{C}$ or better in five subjects including the English language. Ndebele and Shona are not regarded as substitutes of English although they are also languages. Thondhlana in Burnaby and Reyhner (2002) notes that notes that in Zimbabwe without English language one cannot be considered for further education and employment. Guo and Beckett (2007) point out that English is a precondition for employment and promotion, and many professionals invest heavily in English language learning because it is used as a yardstick to measure general competence. This demonstrates that the linguistic situation in Zimbabwe forces the people to embrace the English language and see no necessity to push for an official language policy that also recognizes the indigenous languages of Zimbabwe.

The use of English as an official language of learning has seen the majority of Zimbabweans becoming bilingual. In schools the learners use English in learning all the other subjects except when learning Shona or Ndebele where the respective language is used. Ndebele and Shona, in school are used for communication amongst peers. These two languages are also used at home and therefore for one to become bilingual is inevitable in the Zimbabwean context. The issue of bilingualism has been received with mixed feelings. Yazici et al (2010) are of the view that "In a bilingual context, the mother tongue plays a key role in a child's social and personal development, in education and in second language learning. Vygotsky (1962) is of the view that access to two languages accelerates the development of metalinguistic skills. It is argued that bilingualism enhances cognitive flexibility, analytic skills and creative thinking. Bilingual education supports children's personal development and assists a positive exchange between two languages and cultures, and the development of knowledge in both languages has a positive effect on children's opportunities to express their feelings, thoughts and needs (Yazici et al, 2010; Hamers and Blanc, 2000; and Thondhlana in Burnaby and Reyhner, 2002). However, Rassool et al (2006), are of different view and they point out that the official language of teaching and learning within nation states is associated with high status knowledge and, as such, constitutes a potent form of cultural capital. They further observe that those who are fully literate in the national language have greater cultural capital to exchange in the labor market than those who have not. Their argument is that even if people are bilingual there is one language which carries more prestige and advantages than the other and the first language speakers of the prestige one will always be at an advantage when it comes to the labor market. When an ex-colonial language is the one that carries advantages, those people who live in the rural areas are always left in the periphery because of lack of exposure and as a result they lag behind when it comes to educational development. In Zimbabwe the children who live in urban areas have greater exposure to the English language because they have adequate human and material resources in schools such as the availability of qualified and experienced teachers and textbooks. They also have access to television which most of its programmes are done in English.

The above situations in the education sector especially the advantages that are attached to English makes it difficult to engage into serious language planning activities, because the people see no need to worry about the other languages when they have the English language which is a vehicle of success. The tendency to view language planning as an activity that promotes a single language or that which lobbies for the inclusion of the use of indigenous languages as 
medium of instruction in formal domains such as education, media, law courts and so on has hindered African countries from coming up with official language policy documents.

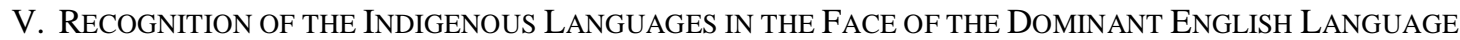

English is fast becoming a global language but the idea of a global language was suggested first in Europe in the $17^{\text {th }}$ century (Etzioni, 2008); second by Comenius in 1938 (Etzioni, 2008); thirdly by Mauro E. Mujica, Chairman of US English (Kayman, 2004) and later emphasized by Crystal (1997), who advocated for and pointed out that English is already a global language. These ideas may have been triggered by the idea of a single language that is understood by all the people in the bible in Genesis 11vs 1-9 on issues about the tower of Babel. The wide use of English in a wide geographical space global has trivialized the use of indigenous African languages. Most people find no motivation in using their indigenous African languages because they can only be used in their locality when speaking with people of the same linguistic background. In Zimbabwe, even people of the same linguistic background use the English language in formal domains such as education, banking sector, parliament, media, etc. Kayman (2004); and Guo and Beckett (2007), view English as a language that has become truly global which no longer belongs to anyone. The very reason that English is now used globally and that it facilitates communication with anyone, anywhere and for whatever purpose means that in any language planning process, English will eventually take the center stage. Most African countries will find it difficult to come up with an official language policy document because any language policy will mean embracing the English language. The official acceptance of English as an ideal language for communication across peoples of multiple linguistic backgrounds in most African countries seems to be perceived as recolonization by Europe. English in a true natural sense is dominant but to accept its dominance is perceived as a defeat. Because English is dominant and accepting its dominance particularly through language policy documents will be perceived as a defeat that then implies that such an assumption will always be a hindrance in coming up with official language policies in African countries.

English has occupied a superior position in Africa because of colonial history. Etzioni (2008) points out that "Although the U.N. or some other such global organization could, theoretically, choose a language to serve as the global language, English is already (and increasingly) occupying this position as a result of the colonial period and postcolonial developments" (p.113). In Zimbabwe, during the colonial period when the country was Southern Rhodesia, the black people who could speak English had access to many opportunities of developing their lives socially and economically and politically. The negotiations for Independence at Lancaster House were done in English and after the independence was gained the dominance of English continued. In parliament and the media, the politicians continued using English language while the indigenous languages were only used when campaigning for votes before elections. Because the politicians who happen to be policy makers find comfort in using English and because they feel that it is easier to communicate with the masses through the use of English which is perceived as neutral they find no push in coming up with an official language policy document. To many policy makers a language policy document is not perceived as a way of rationalizing the use of languages but as a way of protecting and promoting the indigenous languages.

The indigenous languages will hardly be ranked at the same level with English because the English language has been associated with everything that is good. Phillipson (2001), notes that "Throughout the entire post-colonial world, English has been marketed as the language of 'international communication and understanding', economic 'development', 'national unity' and similar positive ascriptions...” (p. 190). It has become a language of communication, business, aviation, entertainment, diplomacy, internet and technology (Guo and Beckett, 2007; Melanovic, 2010; Fishman, 1998; and Crystal, 1997). In multilingual countries such as Zimbabwe, English plays a key role in facilitating communication between people of diverse linguistic backgrounds and also acts as a unifying force. It is also a language of trade across countries regionally and internationally and is also a language that is associated with opportunities as it facilitates access to higher education and to one's economic development. Guo and Beckett (2007) are of the view that English has become a gateway to education, employment and economic and social prestige. Given this background it is clear that Zimbabwe will find it difficult to engage policy makers in drafting a language policy because English is there to cater for communication needs. However sometimes English marginalizes some other members of the society especially those who don't get access to education because English is learnt at school. The increasing dominance of English is empowering the already powerful and leaving the disadvantaged further behind (Guo and Beckettt 2007). What that implies is that those who can't speak English are not part of the development process.

\section{Can Zimbabwe Achieve a Plausible National Language Policy?}

There are a number of questions that need to be answered before thinking about achieving a plausible language policy in Zimbabwe. The following are questions that need to be answered in order to be clear if Zimbabwe can really come up with a clear official national language policy:

1) Why does Zimbabwe need an official national language policy?

2) Who should initiate the drafting of the policy?

3) Who should be involved in the actual drafting of the policy?

4) Does language really need to be planned? 
5) Which languages should be involved and which ones should be left out?

6) What yardsticks or criteria should be used in the selection of languages to be recognized in the policy?

7) What is wrong with the current situation?

8) If there is a language policy document can it really be implemented and practiced, and who should ensure the practice and implementation?

If these questions and fully addressed then it means that a clear official national language policy can be attained in Zimbabwe?

\section{THE Future OF ZIMBABWE’s INDIGENOUS LANGUAGES}

Philiipson (1992) asserts that "globally, what we are experiencing is that English is both replacing other languages and displacing them" (p.27).The higher market value of English is replacing and displacing the indigenous languages of Zimbabwe in more important sectors such as education, finance, law courts, parliament, media, business administration, home affairs, etc. English has become a global language and is now a requirement for decent employment, social status and financial security in various parts of the world, including language minority areas where inhabitants also have to learn the dominant languages of their countries (Guo and Beckett, 2007). In Zimbabwe English occupies the dominant positions and the languages that follow after are Shona and Ndebele. Speakers of other languages find themselves in difficult situations because over and above carrying the burden of English they are also supposed to learn one or both of the indigenous languages which are Shona and Ndebele. This kind of a situation puts their first languages further into the periphery and at the risk of extinction. Speakers of marginalized languages end up finding no importance in them because they are not examined at $\mathrm{O}^{\prime}$ Level and are not a requirement for decent employment. The survival of marginalized languages in Zimbabwe is rather at risk because over and above being overshadowed by the English language, they are also being preyed on by the dominant indigenous languages which are Shona and Ndebele.

The indigenous languages of Zimbabwe can be protected from extinction through coming up with a language policy. If a language policy is put in place and is not implemented then there is no guarantee that these marginalized languages will be protected. One of the languages that has been forced into extinction in Zimbabwe in Nyubi which was spoken in the mountainous areas of Matopo. A research that was carried out in 2010 showed that there were only two remaining speakers of the language and these two speakers were at an advanced age. Indications showed that the Nyubi language was forced into extinction by the Ndebele language. Another language that is showing signs of extinction in Zimbabwe is the San language spoken in Bulilima in Plumtree and Mgodimasili in Tsholotsho. The San language is also being forced into extinction by the dominant and the prestigious Ndebele in Tsholotsho and Plumtree although the language of the majority in Plumtree and Tsholotsho is Kalanga which is also a marginalized language. The San people have in many instances raised some concerns that they are being marginalized when it comes to development projects. During the land reform programme they were not included and the fact that they have always been nomads and they now want to be subsistence farmers is not being taken into full consideration.

The linguistic situation in Zimbabwe is an interesting one in that whilst the country might not be having an official national language policy there still exist a scenario regarding the use of languages. The existing scenario regarding linguistic situation is not written down but is being practiced. Shona and Ndebele are the dominating indigenous languages and they sometimes replace English which is the official language although Shona enjoys a better status than Ndebele. Because there are three dominating languages in Zimbabwe which the majority of the population speaks and there is a perceived idea that there is 'a natural language policy', the policy makers find no obligation in coming up with an official language policy document. However if there could be an official language policy each and every citizen of Zimbabwe will understand his or her place in the linguistic landscape and know how to get involved in the development of the country. One of the differences between political parties in Zimbabwe concerning the draft constitution was to regard sixteen languages of Zimbabwe as official (The Standard 23 September 2012). In Zimbabwe, those who need a national language policy, that is the marginalized linguistic groups have no power to push for it, and those who have the power to push for it, that is, the political elites don't need it because they have no languages to protect. It for this reason why it is questioned in this paper whether attaining a national language in Zimbabwe will be a myth or a reality.

\section{CONCLUSION}

If a language policy is to be achieved in Zimbabwe, there is need for commitment by the policy makers, the politicians and those who want the official recognition of their languages. It has been shown that the twenty-first century has seen the dominance of English language to the extent that is now being regarded as a global language. Its importance in Zimbabwe and other African countries has hindered the drafting of official language policy documents because of the feeling that it caters for all communication needs. It has also been shown in this paper that despite the importance in using English language in education bilingualism is also important as it facilitates development as well. The paper has shown that coming up with a language policy in Zimbabwe is a myth because after all the declarations, suggestions, acts and recommendations have been done nothing has so far taken place regarding coming up with an official language policy. The language policy of Zimbabwe if it comes into existence will protect the marginalized 
languages from extinction but those who are responsible for coming up with policies find no urgent need to come up with such a policy because they don't see the necessity and because of the feeling that the English language acts as a unifying force in a multilingual country like Zimbabwe.

\section{REFERENCES}

[1] Burnabay, B. J. and Reyhner, J.A. (eds) (2002). Indigenous language Across the Community. Arizona: Northern Arizona University.

[2] Coulmas, F. (1998). Language Rights, Interests of States, Language groups and the Individual. Language Sciences. 20 : 63-72.

[3] Crystal, D. (1997). English as a Global Language. Cambridge: Cambridge University Press.

[4] Engin, A. S. (2009). 'Second Language Learning Success and Motivation.' Social Behavior and Personality. Vol 37, 8: 10351042.

[5] Etzioni, A. (2008). ‘A Global Community Building Language?' International Studies Perspectives. 9: 113-127.

[6] Fishman, J. A. (1998). ‘The New Linguistic Order’ Foreign Policy. 26-40.

[7] Government of Zimbabwe. (1987). Zimbabwe Education Act. Harare: Zimbabwe Government printers.

[8] Guo, Y. and Beckett, G. H. (2007). 'The Hegemony of English As a Global Language: Reclaiming Local Knowledge and Culture in China' Convergence. Vol XL, 1-2: 117-131.

[9] Hachipola, S. (1998). A Survey of Minority Languages in Zimbabwe. Harare: University of Zimbabwe Publications.

[10] Hadebe, S. (2002). The Standardisation of the Ndebele Language Through Dictionary-making. Harare: Allex Project, University of Zimbabwe.

[11] Hamers, J. F. and Blanc, M. H. A. (2000). Bilinguality and Bilingualism. Cambridge: Cambridge University Press.

[12] Kayman, M. A. (2004). 'The State of English as a Global Language: Communicating Culture' Textual Practice. Vol 18, 1: 1-22.

[13] Mamdani, M. (1996). Citizen and Subject: Contemporary Africa and the Legacy of Late Colonialism. Princeton: Princeton University Press.

[14] May, S. (2008). Language and Minority Rights. Ethnicity, Nationalism and the politics of language. New York: Routledge.

[15] Mazrui, A. A. and Mazrui, A.M. (1998). The Power of Babel. Language and Governance in the African Experience. Oxford: James Currey Ltd.

[16] Mazrui, A. (2012). The Asmara Declaration on African Languages: A critical Reappraisal. Key address delivered at the Annual Conference of African Linguistics at Ohio University.

[17] Mutasa, D.E. (2006). African Languages in the 21st Century: The Main Challenges. Pretoria: Simba Guru Publishers.

[18] Mumpande, I. (2006). Silent Voices. Indigenous Languages in Zimbabwe. Harare: Weaver Press.

[19] Ndhlovu, F. (2009). The Politics of language and Nation building in Zimbabwe. Bern: Peter Lang.

[20] Organization of African Unity, (1986). DRAFT: 'Language Plan of Action for Africa.'

[21] Peresuh, M. and Masuku, J. (2002). 'The Role of the Primary Language in the Bilingual-Bicultural Education in Zimbabwe.' Zambezia. Vol XXIX, I: 27-37.

[22] Phillipson, R. (1992). Linguistic Imperialism. Oxford: Oxford University Press.

[23] Phillipson, R. (2001). 'English for Globalisation or for World's People' International Review of Education. Vol 47, 3-4: 185200.

[24] Phillipson, R. (2009). Linguistic Imperialism Continued. New Delhi: Orient Blackswan Pvt Ltd.

[25] Rassool, N. et al (2006). 'Language and Development in Multilingual Settings: A Case Study okf Knowledge Exchange and Teacher Education in South Africa.' Review of Education. No 52: 533-552.

[26] The Asmara Declaration on African Languages and Literatures (17 January 2000).

[27] The Harare Declaration on African Languages. 1997: Intergovernmental Conference of Ministers on Language Policies in Africa: Harare: 20-21 March 1997.

[28] The Standard. 23 September 2012. Harare.

[29] UNESCO. (1997). Intergovernmental Conference on Language Policies in Africa. Harare: UNESCO.

[30] Vygotsky, L. S. (1962). Thought and Language. Cambridge: Massachusetts Institute of Technology Press.

[31] Webb, V. and Sure, K. (2000). African Voices. Oxford: Oxford University Press.

[32] Yazici, Z. et al. (2010). 'How Bilingual is Bilingual? Mother-tongue Proficiency and Learning through a Second Language.' International Journal of Early Years Education. Vol 118, 3: 259-268.

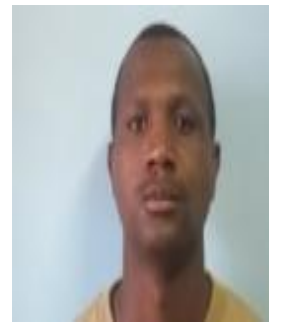

Raphael Nhongo was born in Bulawayo, Zimbabwe on the $7^{\text {th }}$ of December in 1980 . He did his primary education at two different primary schools in Bulawayo and his high school education at Hamilton Boys High School in Bulawayo as well. He did his honors degree in African Languages and Culture from 2001 to 2005 at Midlands State University in Gweru, Zimbabwe and his master's degree in African Languages and Culture from 2006 to 2008 at the same university. He is currently doing a PhD with the University of Fort Hare in South Africa.

He worked at Great Zimbabwe University as a teaching assistant from 2007 to 2008, worked at Lupane State University as a teaching assistant and lecturer from 2008 to 2009. Currently he is working at Midlands State University as a lecturer in the department of African Languages and Culture. He has published two articles in two different journals and has a number of researches going on in the fields of language policy and planning; oral literature; onomastics and theoretical linguistics. 